\title{
Mechanosynthesis and characterization of Hydrotalcite like Mg-Al-
}

\section{$\mathrm{SO}_{4}$-LDH}

\author{
Abbas Fahami ${ }^{\mathrm{a}^{*}}$, Gary W. Beall ${ }^{\mathrm{b}, \mathrm{c} \dagger}$, \\ ${ }^{a}$ Materials Science, Engineering and Commercialization Program, Texas State University, San Marcos \\ 78666, TX, USA \\ ${ }^{b}$ Department of Chemistry and Biochemistry, Texas State University, San Marcos 78666, TX, USA \\ ${ }^{C}$ Physics Department, Faculty of Science, King Abdulaziz University, Jeddah, 21589, Saudi Arabia
}

Dr. Abbas Fahami

fahami@txstate.edu

Tel: +1-512-960-0009

Fax: +1-512-245-8095

${ }^{\dagger}$ Corresponding author: Dr. Gary W. Beall

gb11@txstate.edu

Tel: $+1-512-245-8796$

Fax: +1-512-245-8095

Postal Address: $\quad$ Department of Chemistry and Biochemistry, Texas State University, 601 University Dr. San Marcos 78666, TX, USA 


\begin{abstract}
Sulfate intercalated $\mathrm{Mg}$-Al layered double hydroxides $\left(\mathrm{Mg}-\mathrm{Al}-\mathrm{SO}_{4}-\mathrm{LDH}\right)$ was successfully synthesized by the one step mechanochemical activation method followed by subsequent water washing and aging. Pursuant XRD and FTIR data indicates, product with high purity was obtained after 60 min milling. Results demonstrated that the structural features of Mg-Al- $\mathrm{SO}_{4}$-LDH were affected strongly by milling time (30-900 min) so that interlayer spacing of LDH showed upward trend with some fluctuation. Microscopic analysis showed rounded platelet structure with the average particle size of 50$100 \mathrm{~nm}$. A facile synthesis method was employed and $\mathrm{Mg}-\mathrm{Al}-\mathrm{SO}_{4}-\mathrm{LDH}$ was characterized by complementary physical techniques.
\end{abstract}

Keywords: $\mathrm{Mg}-\mathrm{Al}-\mathrm{SO}_{4}-\mathrm{LDH}$; Mechanochemical activation; Structural features; Electron microscopy.

\title{
1. Introduction
}

Hydrotalcites (HTs) with layered double hydroxides (LDH) structure are anionic clays with chemical formula is $\mathrm{Mg}_{1-}$ ${ }_{\mathrm{X}} \mathrm{Al}_{\mathrm{X}}(\mathrm{OH})_{2} \mathrm{~A}^{n-} \mathrm{x}$, where $\mathrm{A}^{n-}$ represents the charge balancing anions such as $\mathrm{CO}_{3}{ }^{2-}, \mathrm{Cl}^{-}, \mathrm{SO}_{4}{ }^{2-}, \mathrm{OH}^{-}$or $\mathrm{NO}_{3}{ }^{-}[1]$. The carbonate ion among those anions is easily trapped in LDH as soon as exposed to air and moisture. HTs layer structure owing to versatile applications can be modified by exchanging of other anions like $\mathrm{SO}_{4}{ }^{2-}[2]$. Generally, sulfate intercalated $\mathrm{LDH}\left(\mathrm{Mg}-\mathrm{Al}-\mathrm{SO}_{4}-\mathrm{LDH}\right)$ possesses versatile properties such as ion exchangers, fire retardants, base catalyst, potential capability of targeted delivery of nucleotides or drugs and water treatment $[3,4]$.

From synthesis viewpoint, many different chemical techniques have been employed for fabrication of HTs, which include co-precipitation at different $\mathrm{pH}$ [5], hydrolysis [6], sol-gel [7], Microwave-assisted structure reconstruction [8], hydrothermal [9], sonication [10] and mechanical alloying (MA) [11]. Mechanochemical activation method owing to its simplicity and versatility has recently been receiving particular attention as an alternative method to prepare mass production with appropriate structural characteristics [12]. In this process, melting is not necessary and a homogenous product is achieved from reagents mixture [13].

In this paper, sulfate intercalated $\mathrm{Mg}$-Al layered double hydroxides $\left(\mathrm{Mg}_{0.8} \mathrm{Al}_{0.2}(\mathrm{OH})_{2}\left(\mathrm{SO}_{4}\right)_{0.1}\right)$ was prepared via mechanochemical activation followed by water washing and aging at $80^{\circ} \mathrm{C}$ for $1 \mathrm{~h}$. However, no specific documentation has been reported on $\mathrm{Mg}_{0.8} \mathrm{Al}_{0.2}(\mathrm{OH})_{2}\left(\mathrm{SO}_{4}\right)_{0.1}$ using mechanochemistry so far. Furthermore, phase behaviour, and structural features including interlayer spacing, unit cell volume of lattice as well as morphological properties of products

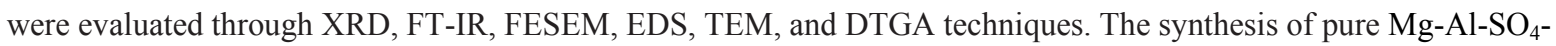
LDH reported here can be a promising candidate for using in water treatment applications.

\section{Materials and methods}


Magnesium chloride (99\%, ACROS), Aluminum chloride (99\%, ACROS), Sodium hydroxide pellets (97\%, ACROS), and Sodium sulfate (Merck) were purchased and used as received without further purification. To synthesize $\mathrm{Mg}_{0.8} \mathrm{Al}_{0.2}(\mathrm{OH})_{2}\left(\mathrm{SO}_{4}\right)_{0.1}$, the desired amounts of $\mathrm{MgCl}_{2}, \mathrm{AlCl}_{3}, \mathrm{Na}_{2} \mathrm{SO}_{4}$ and $\mathrm{NaOH}$ were milled at different milling times $(30,60,300,600$, and $900 \mathrm{~min})$ in a high energy ball mill (8000M Mixer/Mill) utilizing hardened chromium steel vials (vol. $65 \mathrm{ml}$ ) under air atmosphere. The weight ratio of ball-to-powder (BPR) was 10:1. The powders were washed three times with deionized water $(20 \mathrm{ml})$ on a paper filter, and then were aged under oven at $80^{\circ} \mathrm{C}$ for $1 \mathrm{~h}$. The final composition was adjusted according to the following reaction (R1):

$0.8 \mathrm{MgCl}_{2}+0.2 \mathrm{AlCl}_{3}+0.1 \mathrm{Na}_{2} \mathrm{SO}_{4}+2 \mathrm{NaOH} \rightarrow \mathrm{Mg}_{0.8} \mathrm{Al}_{0.2}(\mathrm{OH})_{2}\left(\mathrm{SO}_{4}\right)_{0.1}+2.2 \mathrm{NaCl}$

Phase identification was carried out using Bruker D8 Advance ECO using $C u-K_{\alpha}$ radiation $(\lambda \approx 1.54 \AA)$. The patterns were scanned from 5 to 80 degrees $2 \theta$ at a step size of 0.03 degrees. The XRD profiles were compared to standards compiled by the Joint Committee on Powder Diffraction and Standards (JCPDS), which involved card \#14-0191 for Hydrotalcite, \#44-1482 for Brucite, and \#1-071-1176 for Periclase.

Fourier transform infrared spectroscopy (FT-IR, Bruker Tensor 27, USA) was used to assess the functional groups of products. All spectra were recorded at ambient temperature in the range $4000-400 \mathrm{~cm}^{-1}$. Morphological appraisal of Mg$\mathrm{Al}^{-S_{4}-\mathrm{LDH}}$ was executed using FE-SEM (FEI Helios Nanolab 400 SEM) and TEM (JEOL JEM 1200 EXII). EDS analysis attached to the FESEM was used to determine the elemental composition. Thermal analysis was carried out with a TGA (TA Q50 Thermogravimetric Analyzer) during heating in an argon atmosphere at a rate of $10^{\circ} \mathrm{C} / \mathrm{min}$ from room temperature to $800^{\circ} \mathrm{C}$.

\section{Results and discussions}

Fig 1 presents the XRD patterns, interlayer spacing $(d)$, lattice constants ( $a$, and $c$ ), and unit cell volume of the samples after washing with deionized water followed by aging as a function of milling time (30-900 min). Based on Fig. 1a, the main products of 30 min milling were Brucite and HT. The presence of Brucite indicates mechanochemical reaction was not completed, while it was almost vanished with increasing of milling time up $60 \mathrm{~min}$, and a pure phase composition of sulfate intercalated HT was formed. This trend continued for the 300 min milled specimen with slight increase in peaks intensity of HT and a partial trace of Periclase (MgO). This confirms that HT decomposed slightly as the milling time increased. Further increase in the milling time up to $900 \mathrm{~min}$ led to further sharpening of the diffraction peaks of Periclase, which is believed to be caused by more decomposition of HT. It should be mentioned that all sharp peaks corresponding to sulfate intercalated HT were shifted gradually toward lower d spacing owing to the rise of the unit cell volume of HT and the presence of sulfate ions instead of carbonate ions. The interlayer spacing $(d)$ of milled samples was determined by averaging the basal peaks according to the equation (I) [14]: 
$d=\frac{1}{n}\left(d_{(003)}+2 d_{(006)}+\cdots+n d_{(00 n)}\right)$

Based on Fig 1b, The basal spacing between layers of $\mathrm{Mg}_{0.8} \mathrm{Al}_{0.2}(\mathrm{OH})_{2}\left(\mathrm{SO}_{4}\right)_{0.1}$ was strongly influenced by milling time so that it escalated from $7.828 \pm 0.001$ to $7.942 \pm 0.002(30-600 \mathrm{~min})$ and then decreased to $7.878 \pm 0.001$ for 900 milled sample. The change from tetrahedral $\mathrm{SO}_{4}{ }^{2-}$ to trigonal planar $\mathrm{CO}_{3}{ }^{2-}$ also contributes to this expansion.
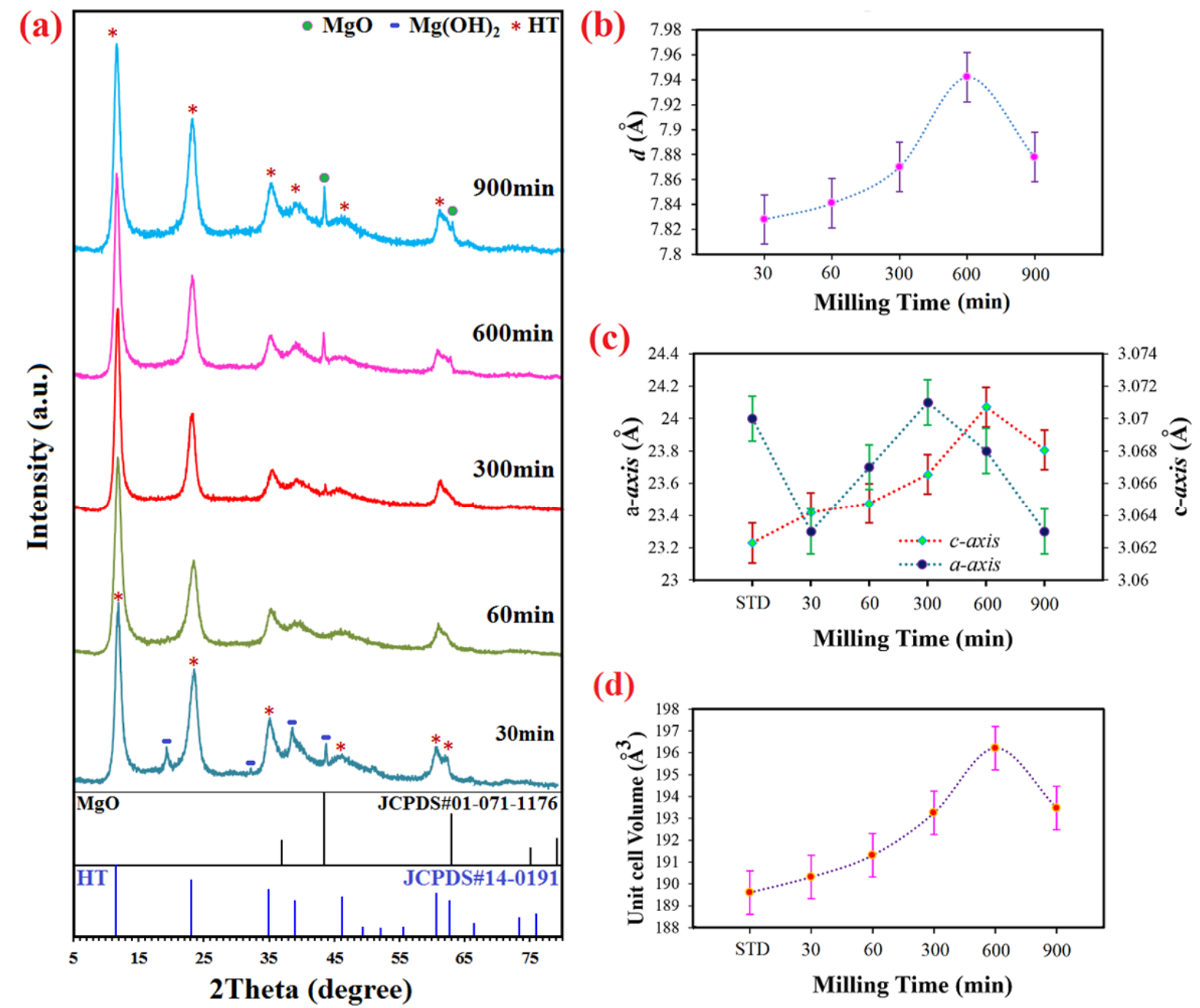

(d)

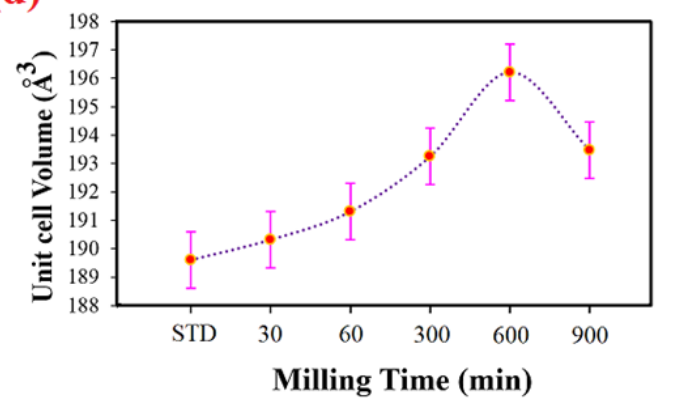

Fig. 1 (a) XRD patterns, (b) interlayer spacing, (c) lattice parameters and (d) the unit cell volume of the milled samples as a function of milling time (30-900 $\mathrm{min})$.

The lattice parameters (a, and c) can be calculated from the following relation (II) for two Miller's planes of (003) and (110):

$\frac{1}{d^{2}}=\frac{4}{3} \frac{h^{2}+h k+k^{2}}{a^{2}}+\frac{l^{2}}{c^{2}}$

where $h, k$, and $l$ are the Miller indices. The unit cell volume of samples was also computed using the following equation (III) [15]:

$V=\left(a^{2} c\right) \sin 60^{\circ}$ 
Fig. $3 \mathrm{~b}$ and $\mathrm{c}$ exhibits the lattice constants and unit cell volume of milled nanopowders as a function of milling time.

Note, the data obtained from equation (III) should be compared to the unit cell parameters reported for the standard HT.

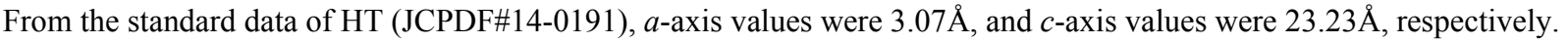

The comparison study of those data reveals that the $a$-axis and $c$-axis values were different; however it shows an overall upward trend for milled samples with some fluctuation as milling time increased (30-900 min). According to Fig. 3c, unit cell volumes of the milled powders increased slowly from $190.32 \pm 0.01$ to $196.22 \pm 0.02\left(\AA^{3}\right)$ as milling time rose (30-600 min) and then declined to $193.48 \pm 0.02 \AA^{3}$ for 900 min milled sample. From the data, it is clear that the disparities in values of unit cell volume resulted mainly from increases in the $c$ axis values, rather than $a$ axis ones and could possibly attributed to the change a tetrahedral arrangement of sulfate ion as compared to trigonal planar of carbonated ion. These findings prove that the structural features of the mechanosynthesized $\mathrm{Mg}-\mathrm{Al}-\mathrm{SO}_{4}-\mathrm{LDH}$ were affected considerably by the milling time.

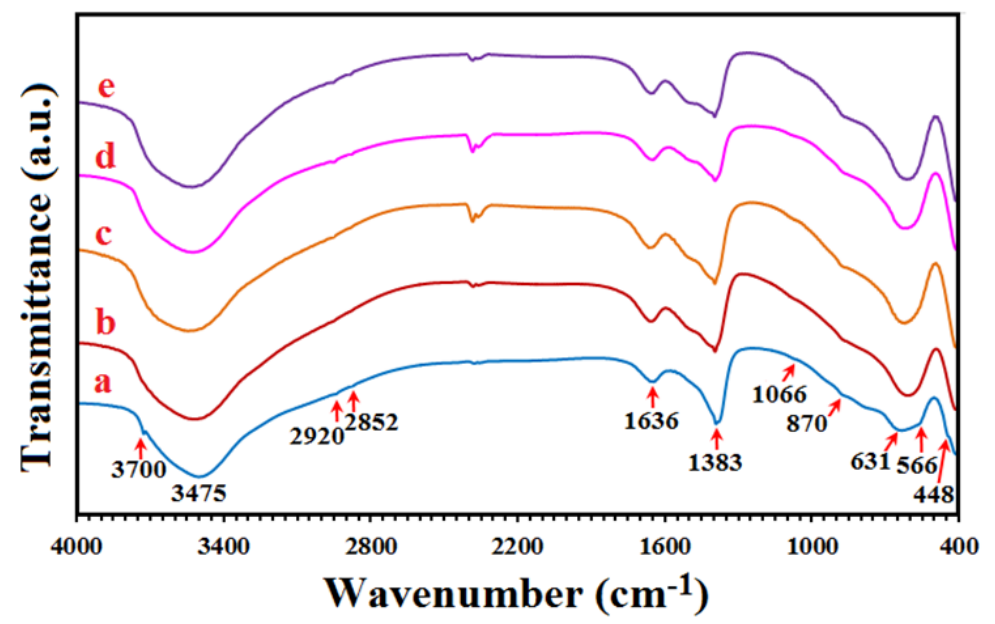

Fig. 2 FT-IR spectra of milled specimens (Mg-Al-SO 4 -LDH) as a variation of milling time; (a) 30, (b) 60, (c) 300, (d)

$$
\text { 600, and (e) } 900 \mathrm{~min} \text {. }
$$

The FT-IR spectra of samples as a function of milling time were displayed in Fig. 2. The spectrum of 30 min milled sample exhibited a narrow weak band corresponding to the stretching vibrations of Brusite $\left(3700 \mathrm{~cm}^{-1}\right)$, a broad Hydroxyl band $\left(v_{2}\right)$ at $3475 \mathrm{~cm}^{-1}$ (owing to sorbed water), a weak water band at $1636 \mathrm{~cm}^{-1}$, and two bands at 556 and 448 $\mathrm{cm}^{-1}$ (due to metal-oxygen bond in the Brucite like lattice) [16]. Two weak bands at around 2920 and $2852 \mathrm{~cm}^{-1}$ (the shoulder of graph) were possibly owing to the hydrogen bonded $(\mathrm{OH})$ stretching of intercalated water molecule [17]. The absorption bands at around $1383\left(v_{3}\right), 870\left(v_{2}\right)$, and $631 \mathrm{~cm}^{-1}\left(v_{4}\right)$ shows the stretching vibration of $\mathrm{CO}_{3}{ }^{2-}$, which is owing to the absorption of $\mathrm{CO}_{2}$ from the air by Brucite [18]. The FTIR spectra of $\mathrm{Mg}-\mathrm{Al}-\mathrm{SO}_{4}-\mathrm{LDH}$ at $1066 \mathrm{~cm}^{-1}$ were attributed to the bending mode of interlayer sulfate ions [17]. With increasing of milling time up to 60 min, the Brucite band 
completely disappeared indicating the reaction of magnesium hydroxide with the other reagents. This supported the results obtained from XRD data.

The FESEM and TEM images of 60 min milled sample $\left(\mathrm{Mg}_{0.8} \mathrm{Al}_{0.2}(\mathrm{OH})_{2}\left(\mathrm{SO}_{4}\right)_{0.1}\right)$ are shown in Fig. 3. According to Fig. $3 \mathrm{a}$, the product had a rounded platelet structure composed of several fine particles. Pursuant their relatively large specific surface area of particles, the product had high tendency to agglomeration. During milling, the system included one ductile constituent $(\mathrm{NaOH})$ and three brittle components $\left(\mathrm{Na}_{2} \mathrm{SO}_{4}, \mathrm{MgCl}_{2}\right.$ and $\left.\mathrm{AlCl}_{3}\right)$. Sodium chloride was formed owing to the hygroscopic nature of Halite, and followed by the formation of a ductile-brittle system. With continuous milling, both ductile and brittle particles got further refined and the interlamellar spacing dropped. Ultimately, product with the layered structure was developed when equilibrium between fracturing brittle particles by trapping and ductile constituents by work hardening was established. From EDS spectrum of 60 min milled specimen, the main elements were oxygen, magnesium, aluminum, carbon, and sulfur. In addition, no other stable contaminants were detected. Based on TEM image in Fig. 3b, smaller particles were mostly rounded platelet shape with a mean size of around 50-100 nm.
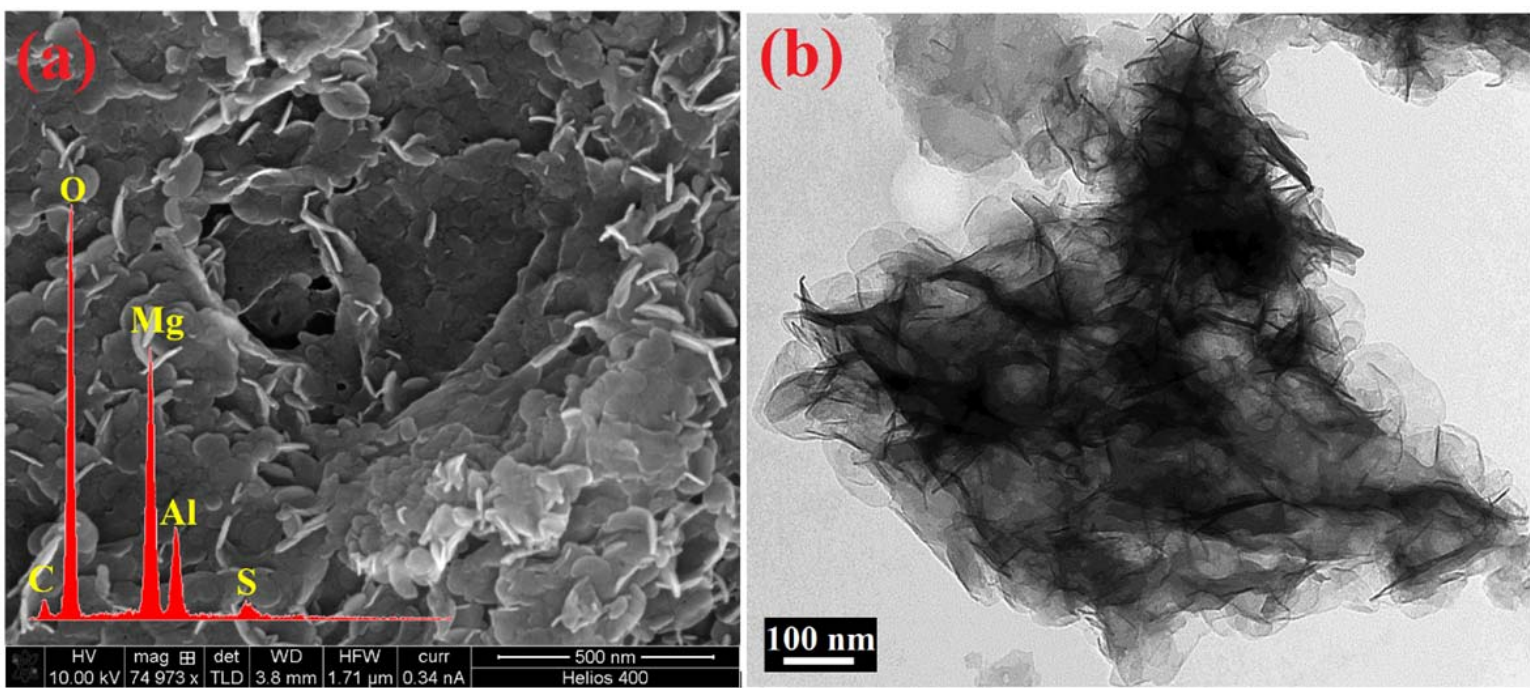

Fig. 3 Morphological features of 60 min milled sample (Mg-Al-SO 4 -LDH): (a) FE-SEM image \& EDS spectrum and (b)

TEM image.

Figure 7 gives an overlay of the differential thermogravimetric analysis (DTGA) disclosing the degradation mechanism under the recording conditions for 60 min milled sample $\left(\mathrm{Mg}_{0.8} \mathrm{Al}_{0.2}(\mathrm{OH})_{2}\left(\mathrm{SO}_{4}\right)_{0.1}\right)$. As reflected in DTGA trend, the thermal decomposition process covers two stages, which were ascribed to processes like the structural dehydroxylation, and the removal of the interlayer anions. The first mass loss of $\sim 2.9 \%$ occurred between around $133^{\circ} \mathrm{C}$ and $215^{\circ} \mathrm{C}$ which may be contributed to the elimination of the interlamellar water but not high enough for the removal of the carbonate anions or hydroxyl groups. From approximately $215^{\circ} \mathrm{C}$ to $514^{\circ} \mathrm{C}$, the second mass loss was the largest occurring at $388^{\circ} \mathrm{C}$ accounting for $31.7 \%$, which associated to the interlayer anions loss. In this stage, decarbonation and dehydroxylation were proposed to have been removed. It is worthy to note that the conventional HTs having carbonate 
anions had a decomposition temperature of $310^{\circ} \mathrm{C}$ [19]. However, the growth in decomposition temperature may demonstrate that sulfate anions have been successfully intercalated in $\mathrm{LDH}$. From $514^{\circ} \mathrm{C}$, there is a constant residual mass associated to the formation of the magnesium and aluminum oxide, corresponding to $\sim 40 \%$ of the initial mass.

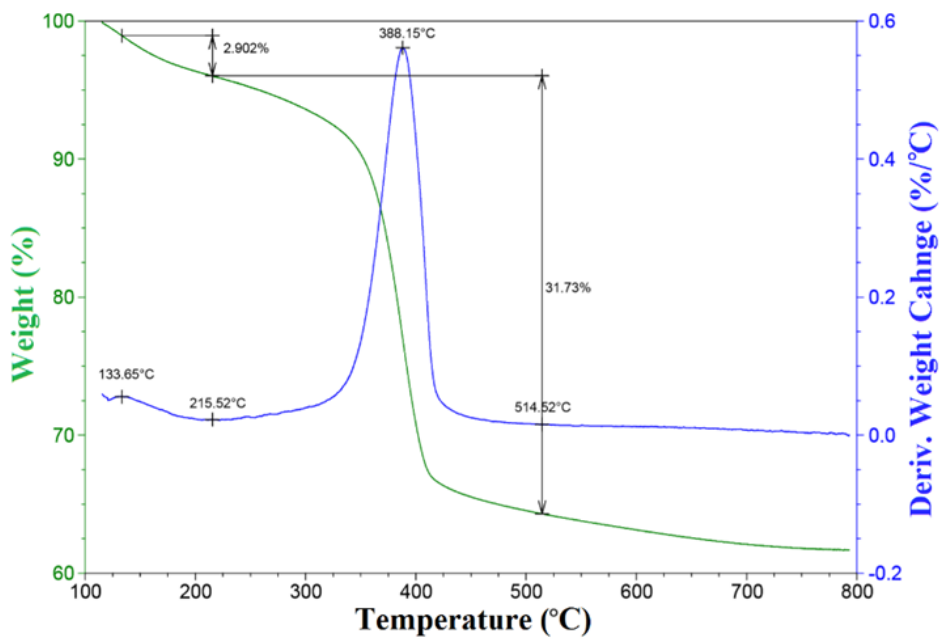

Fig. 4 DTGA of 60 min milled sample $\left(\mathrm{Mg}-\mathrm{Al}-\mathrm{SO}_{4}-\mathrm{LDH}\right)$ as a function of temperature.

\section{Conclusions}

In this report, one-step mechanochemical synthesis of $\mathrm{Mg}-\mathrm{Al}-\mathrm{SO}_{4}-\mathrm{LDH}$ was investigated. Results showed that the structural features of product affected strongly by milling time (30-900 min) so that the interlayer space of resulting solid was expanded as milling time increased. Based XRD and FTIR spectra, a pure phase composition of sulfate intercalated HT was formed after 60 min milling. Microscopic observations showed a rounded platelet structure of product containing small particles with mean size of 50-100 nm. From EDS spectrum, no other chemically stable impurities were detected. Based on the DTGA data of Mg-Al- $\mathrm{SO}_{4}-\mathrm{LDH}$, two mass loss characteristics events of the thermal decomposition of the LDH were observed which indicates that sulfate anions have been successfully intercalated in LDH structure. Finally, the mechanosynthesized $\mathrm{Mg}-\mathrm{Al}-\mathrm{SO}_{4}-\mathrm{LDH}$ with nanosized particles can be useful as a carrier and reservoir for target delivery and water treatment.

\section{Acknowledgement}

This research was supported by the National Science Foundation (PREM center for interfaces, DMR-1205670), and the Robert A. Welch Foundation (AI-0045).

\section{References}

[1] Sampieri A, Fetter G, Villafuerte-Castrejon ME, Tejeda-Cruz A, Bosch P, Beilstein J Nanotechnol 2011;2: 99-103.

[2] Sanderson BA, Sowersby DS, Crosby S, Goss M, Lewis LK, Beall GW, Biointerphases 2013;8:8. 
[3] Wang Q, Tay HH, GuoZ, Chen L, Liu Y, Chang J, Zhong Z, Luo J, Borgna A, Appl Clay Sci 2012;55:18-26.

[4] Choy JH, Choi SJ, Oh JM, Park T, Appl Clay Sci 2007;36:122-132.

[5] Kovanda F, Grygar T, Dornicak V, Solid State Sci 2003;5:1019-1026.

[6] Hibino T, Ohya H, Appl Clay Sci 2009;45:123-132.

[7] Paredes SP, Fetter G, BoschP, Bulbulian S, J Mater Sci 2006;41:3377-3382.

[8] Benito P, Guinea L, Labajos FM, Rives V, J Solid State Chem 2008;181:987-996.

[9] Labajos FM, Rives V, Ulibarri MA, J Mater Sci 1992;27:1546-1552.

[10] Climent MJ, Corma A, Iborra S, Epping K, Velty A, J Catal 2004;225:316-326.

[11] Khusnutdinov VP, Isupov VP, Inorg Mater 2008;44:263-267.

[12] Fahami A, Ebrahimi-Kahrizsangi R, Nasiri-Tabrizi B, Solid State Sci 2011;13:135-141.

[13] Nasiri-Tabrizi B, Fahami A, Ebrahimi-Kahrizsangi R, Ceram Inter 2013;39:5751-5763.

[14] Tronto J, Bordonal AC, Naal Z, Valim JB, Materials Science-Advanced Topics, (2013) ISBN: 978-953-51-1140-5.

[15] Fahami a, Nasiri-Tabrizi B, Ceram Int 2014;40:14939-14946.

[16] Xu ZP, Walker TL, Liu KL, Cooper HM, Lu GQM, Bartlett PF, Int J Nanomed 2007;2:163-174.

[17] Acharya H, Srivastava SK, Bhowmick AK, Compos Sci Technol 2007;67: 2807-2816.

[18] Yanga W, Kima Y, Liub PKT, Sahimia M, Tsotsisa TT, Chem Eng Sci 2002;57:2945 - 2953.

[19] Theiss FL, Palmer SJ, Ayoko GA, Frost RL, J Therm Anal Calorim 2012;107:1123-1128. 


\section{List of Figures Caption}

Fig. 1 (a) XRD patterns, (b) interlayer spacing, (c) lattice parameters and (d) the unit cell volume of the milled samples as a function of milling time (30-900 min).

Fig. 2 FT-IR spectra of milled specimens (Mg-Al-SO ${ }_{4}-\mathrm{LDH}$ ) as a variation of milling time; (a) 30, (b) 60, (c) 300, (d) 600, and (e) $900 \mathrm{~min}$.

Fig. 3 Morphological features of 60 min milled sample (Mg-Al-SO $-\mathrm{LDH})$ : (a) FE-SEM image \& EDS spectrum and (b) TEM image.

Fig. 4 DTGA of 60 min milled sample (Mg-Al-SO $\left.{ }_{4}-\mathrm{LDH}\right)$ as a function of temperature. 